\title{
Preservação Digital em Mídias Sociais: uma revisão sistemática de literatura
}

\author{
Flavio Ribeiro Córdula \\ Universidade Federal da Paraíba, Departamento de Ciência da Informação, João Pessoa, PB, Brasil \\ cordulaflavio@gmail.com \\ Sandra de Albuquerque Siebra \\ Universidade Federal de Pernambuco, Departamento de Ciência da Informação,Recife, PE, Brasil \\ sandra.siebra@gmail.com \\ Wagner Junqueira de Araújo \\ Universidade Federal da Paraíba, Departamento de Ciência da Informação, João Pessoa, PB, Brasil \\ wagnerjunqueira.araujo@gmail.com
}

DOI: https://doi.org/10.26512/rici.v13.n1.2020.24727

Recebido/Recibido/Received: 2019-05-18

Aceitado/Aceptado/Accepted: 2019-10-08

ARTIGOS DE REVISÃO

Resumo: Este artigo teve como objetivo investigar o cenário atual da aplicação de estratégias de preservação digital em mídias sociais, buscando entender, principalmente, quais os conceitos, os desafios e as estratégias envolvidas nesse processo.Para isso, buscou-se uma visão ampliada das produções científicas sobre o tema nas bases SCOPUS, LISA, SciELO e BRAPCI, no período compreendido entre julho de 2013 e julho 2018. Fez-se uso de revisão sistemática de literatura e da bibliometria para tabulações e análises dos dados pesquisados, com base nas diretrizes estabelecidas pelo Preferred Reporting Items for Systematic reviews and Meta-Analyses- PRISMA. Verificou-se um sinal de dissonância entre as pesquisas sobre preservação digital em mídias sociais no Brasil e no mundo.Constatou-se que o tópico mais discutido pelos autores englobou os desafios enfrentados na preservação digital em mídias sociais, entre os quais citaram a seleção do que deve ser preservado e as questões éticas e de privacidade, entre outros. Conclui-se que essa é uma temática de fronteira, interdisciplinar e que possui literatura escassa e predominantemente em língua inglesa.

Palavras-chave: Preservação digital. Mídias sociais. Bibliometria. Revisão de literatura.

\section{Preservación Digital en Medios Sociales: una revisión sistemática de literatura}

Resumen: El presente trabajo tuvo como objetivo investigar el escenario actual de aplicación de estrategias de preservación digital en las redes sociales, para entender, principalmente, cuáles son los conceptos, los desafíos y las estrategias involucradas. Para ello, se realizaron búsquedas de la producción científica sobre esas temáticas en las bases de datos SCOPUS, LISA, SciELO y BRAPCI, en el período comprendido entre julio de 2013 y julio de 2018. Se realizó una revisión sistemática de literatura y se utilizó la bibliometría para las tabulaciones y análisis de los datos, tomando como base las directrices establecidas por el Preferred Reporting Items for Systematic reviews and Meta-Analyses (PRISMA). Se verificó falta de correspondencia entre las investigaciones sobre preservación digital en las redes sociales en Brasil y en el mundo. Se constató que los temas más discutidos por los autores abarcaron los desafíos enfrentados en la preservación digital en las redes sociales, entre los que se destacaron la selección de lo que debe ser preservado, las cuestiones éticas y de privacidad, entre otros. Se concluye que esa es una temática de frontera, interdisciplinar, con escasa literatura, predominantemente, en lengua inglesa.

Palabras clave: Preservación digital. Redes sociales. Bibliometría. Revisión de literatura.

Digital Preservation in Social Media: a systematic literature review 
Abstract: This article aimed to investigate the current scenario of the application of digital preservation strategies in social media, trying to understand, mainly, the concepts, challenges and strategies involved in this process. In order to do so, it was sought a broader view of the scientific productions on the subject at SCOPUS, LISA, SciELO and BRAPCI databases, from July 2013 to July 2018. It was used a systematic review of literature and bibliometrics, for tabulations and analysis of the data surveyed, based on the guidelines established by the Preferred Reporting Items for Systematic Reviews and MetaAnalyzes - PRISMA. It was identified a sign of dissonance between research on digital preservation in social media in Brazil and in the world. It was verified that the topic most discussed by the authors encompassed the challenges faced in the digital preservation in social media, among which they cited the selection of what should be preserved and ethical and privacy issues, among others. It was concluded that this is a frontier and interdisciplinary topic and that it has literature scarce and predominantly in the English language.

Keywords: Digital preservation. Social media. Bibliometrics. Literature review.

\section{Introdução}

De acordo com Recuero (2009), o advento da Internet provocou várias mudanças na sociedade e possibilitou que as pessoas se expressassem e socializassem por meio de ferramentas de comunicação mediada por computadores. Essas ferramentas possibilitaram que os usuários "pudessem construir-se, interagir e comunicar com outros atores, deixando, na rede de computadores, rastros que permitem o reconhecimento dos padrões de suas conexões e a visualização de suas redes sociais através desses rastros" (RECUERO, 2009, p. 24).

Entre essas ferramentas, pode-se citar: e-mail, wikis, mensagens instantâneas, sites, blogs e mídias sociais. Estas últimas, foco deste trabalho, podem ser definidas como tecnologias utilizadas, cada vez mais, por empresas e indivíduos, para disseminar informações/conteúdo de forma descentralizada, provocando o compartilhamento de ideias, experiências, opiniões e perspectivas, ao mesmo tempo em que permitem alguma relação entre pessoas (TELLES, 2010).

O que muitos chamam de mídias sociais, compreende um fenômeno complexo,que abarca o conjunto de novas tecnologias de comunicação mais participativas, mais rápidas e mais populares e as apropriações sociais que foram e que são geradas em torno dessas ferramentas. É um momento de hiperconexão em rede, onde estamos não apenas conectados, mas onde transcrevemos nossos grupos sociais e, através do suporte, geramos novas formas de circulação, filtragem e difusão dessas informações (RECUERO, 2011, p. 14, grifo nosso).

Logo, esse tipo de mídia acaba por impactar a forma como as informações são produzidas, tratadas, disseminadas e ficam registradas. Além disso, essa nova base tecnológica pode conter registros da herança cultural, de costumes, fatos, acontecimentos, além de representações do mundo físico e social. Por isso, à medida que as comunidades nessas mídias sociais crescem e o número de usuários aumenta, elas deixam para trás um valioso registro cultural, memorial e histórico da nossa sociedade. Tais registros podem vir a ser utilizados por pesquisadores, historiadores, agências governamentais, instituições, entre outros, para os 
mais diversos fins:seja para melhor compreender o mundo em que se vive ou acontecimentos em um momento no tempo; para dar suporte à implementação de produtos e/ou serviços; para recuperar informações sobre um tema ou evento etc. Dessa forma, pode-se afirmar que a sociedade se beneficiaria com a preservação de dados/informações advindos de mídias sociais, trazendo à tona a necessidade de se pensar estratégias para preservação digital nesse meio.

Preservação digital é um termo utilizado para nomear um conjunto de atividades ou processos responsáveis por assegurar o acesso a longo prazo às informações, aos dados e ao patrimônio cultural existente em formato digital (FERREIRA, 2006). Porém, as características dos conteúdos informacionais digitais originados nas mídias sociais - devido à velocidade de produção, dinamicidade e natureza efêmera - demandam novas formas de tratamento e gestão. Sendo assim, a preservação digital nesse meio é considerada um desafio, uma temática a ser estudada frente às práticas de disseminação da informação e ao uso, à comunicação e ao registro de conteúdos, que poderão gerar novos e dinâmicos documentos digitais (FROHMANN, 2008).

Com base no exposto, a pesquisa relatada neste artigo teve como objetivo investigar, por meio de revisão sistemática de literatura (RSL), o cenário atual da aplicação de técnicas de preservação digital em mídias sociais, buscando entender, principalmente, quais os conceitos, os desafios e as estratégias envolvidas nesse processo. Para isso, se baseou nas diretrizes estabelecidas pelo Preferred Reporting Items for Systematic reviews and Meta-Analyses PRISMA (MOHER et al., 2009) e utilizou a bibliometria para composição da meta-análise.

É importante destacar que, como 19 dos 20 artigos que fizeram parte desta RSL foram escritos em Língua Inglesa, as citações, termos etc. escritos em Língua Portuguesa ao longo deste trabalho e atribuídos às publicações que integram esta RSL foram traduzidos livremente, a fim de serem incorporados a esta pesquisa. Ressalta-se também que, apesar de algumas revisões sistemáticas da literatura incluírem uma seção com referencial teórico após a introdução (p. ex. MIRANDA, 2018), este artigo seguiu a estrutura mais tradicional para este tipo de pesquisa (p. ex. HALL et al., 2016) e apenas alguns conceitos essenciais foram apresentados na introdução.

\section{Metodologia}

Com abordagem exploratória, esta pesquisa é um estudo quanti-qualitativo da produção científica sobre o tema da preservação digital em mídias sociais. Quanto aos procedimentos técnicos, utilizou-se da revisão sistemática de literatura (RSL) em bases de dados online de pesquisa científica. Segundo Miranda (2018, p. 24), as RSL são "estudos das produções científicas sobre determinado tema, em bases de dados referenciadas e em 
específico espaço de tempo". O autor afirma ainda que as RSL podem "situar a pesquisa sobre determinada questão e indicar possíveis lacunas a serem preenchidas com investigações futuras" (MIRANDA, 2018, p. 24). Ao se valer dessas e de outras características, as revisões sistemáticas de literatura vão ao encontro de trabalhos realizados na área de Ciência da Informação.

Esta revisão sistemática de literatura se baseou nas diretrizes estabelecidas pelo Preferred Reporting Items for Systematic reviews and Meta-Analyses - PRISMA (MOHER et al., 2009). Tais diretrizes dão origem a um fluxograma de quatro etapas: identificação, seleção, elegibilidade e inclusão, que direcionam as fases de uma RSL em busca de produção científica útil e válida. Elas dão origem, também, a um checklist com 27 itens que apresenta sugestões nos relatos de revisão sistemática.Além disso, com a intenção de observar a produção científica sobre a temática da preservação digital em mídias sociais, optou-se pela bibliometria para a composição da meta-análise. As métricas utilizadas neste trabalho analisaram os períodos de publicação, as autorias, as fontes de publicação e as palavras-chave.

O critério de inclusão do material a ser analisado seguiu as quatro fases do PRISMA e levou em consideração o objetivo deste estudo - investigação do cenário atual da aplicação de técnicas de preservação digital em mídias sociais. Considerou, ainda, na sua delimitação de tempo, o fato de que estudos e pesquisas sobre essa temática se atualizam constantemente, devido à rapidez com que as tecnologias que sustentam as plataformas de mídia social mudam. Assim, optou-se por um recorte temporal de 5 anos, ou seja, de julho de 2013 a julho de 2018.

A fase de identificação envolve a busca de evidências. Logo, optou-se por realizar a busca de material nas bases de dados internacionais SCOPUS (Elsevier) e Library and Information Science Abstracts - LISA (ProQuest). Ambas as bases são multidisciplinares e de grande representatividade acadêmica em nível mundial. Vale destacar que o acesso a alguns dos textos completos indicados por essas bases só foi possível por intermédio do Portal de Periódicos da Capes, plataforma que possibilita, a pesquisadores, o acesso gratuito a publicações geralmente pagas. Para a busca, foram utilizados termos nos idiomas português e inglês. Destaca-se que mesmo as publicações em outros idiomas possuem metadados - título, resumo, palavras-chave etc. - em Língua Inglesa. Optou-se por incluir material científico de vários tipos, tais como: artigos, livros, capítulos de livros, relatórios, entre outros, desde que publicados e acessíveis. Os termos de busca utilizados foram: preservação digital, rede social e mídia social. Esses termos foram pesquisados na sua forma singular e plural, além de suas expressões equivalentes na Língua Inglesa. 
Ao realizar a pesquisa associando os termos em inglês, 280 publicações foram retornadas, sendo 157 da SCOPUS e 123 da LISA. Já ao utilizar as expressões em português, o número retornado foi 0 (zero). Tal acontecimento provocou a inclusão de duas outras bases de dados com uma maior representatividade de publicações em Língua Portuguesa: a SciELO, que retornou 6 artigos, e a Brapci, com 2. Foram identificadas, assim, um total de 288 publicações: 157 da SCOPUS, 123 da LISA, 6 da SciELO e 2 da Brapci. Destaca-se, aqui, a discrepância entre o número de resultados de pesquisas sobre preservação digital em mídias sociais no Brasil e no mundo.

As fases de seleção, elegibilidade e inclusão são sequenciais e lógicas. Assim, depois da identificação das publicações, eliminou-se, primeiramente, os materiais duplicados - seleção e, em seguida, aqueles que, de acordo com título, resumo, palavras-chave e palavras indexadas por suas respectivas bases de dados, fugiam à temática proposta por esta RSL elegibilidade. As publicações restantes e acessíveis foram baixadas e lidas na íntegra para uma exclusão ou inclusão definitiva, etapa necessária à condução da RSL. A Tabela 1 sumariza as 20 publicações resultantes da aplicação de todas as fases do PRISMA nesta revisão sistemática de literatura.

Como pode ser visualizado na Tabela 1, as bases de dados SCOPUS e LISA retornaram 21 publicações idênticas. Por esse motivo, subtraiu-se esse número do total de publicações de uma delas, a SCOPUS. Assim, das 157 publicações identificadas na SCOPUS, 136 (157 - 21) foram selecionadas e se tornaram elegíveis para inclusão. Dessas 136 publicações, 85 foram excluídas com base nos metadados, ou seja, restaram 51 (136 - 85). Das 51 publicações restantes, 22 tiveram o acesso aos seus textos completos negados, mesmo por meio do Portal de Periódicos da CAPES, ficando, assim, 29 (51 - 22). Essas 29 foram lidas na íntegra, sendo 20 delas descartadas por não seguirem a temática proposta. Por fim, foram selecionadas 9 (29 20) publicações da SCOPUS. 
Tabela 1 - Resumo da aplicação das fases do PRISMA nesta RSL

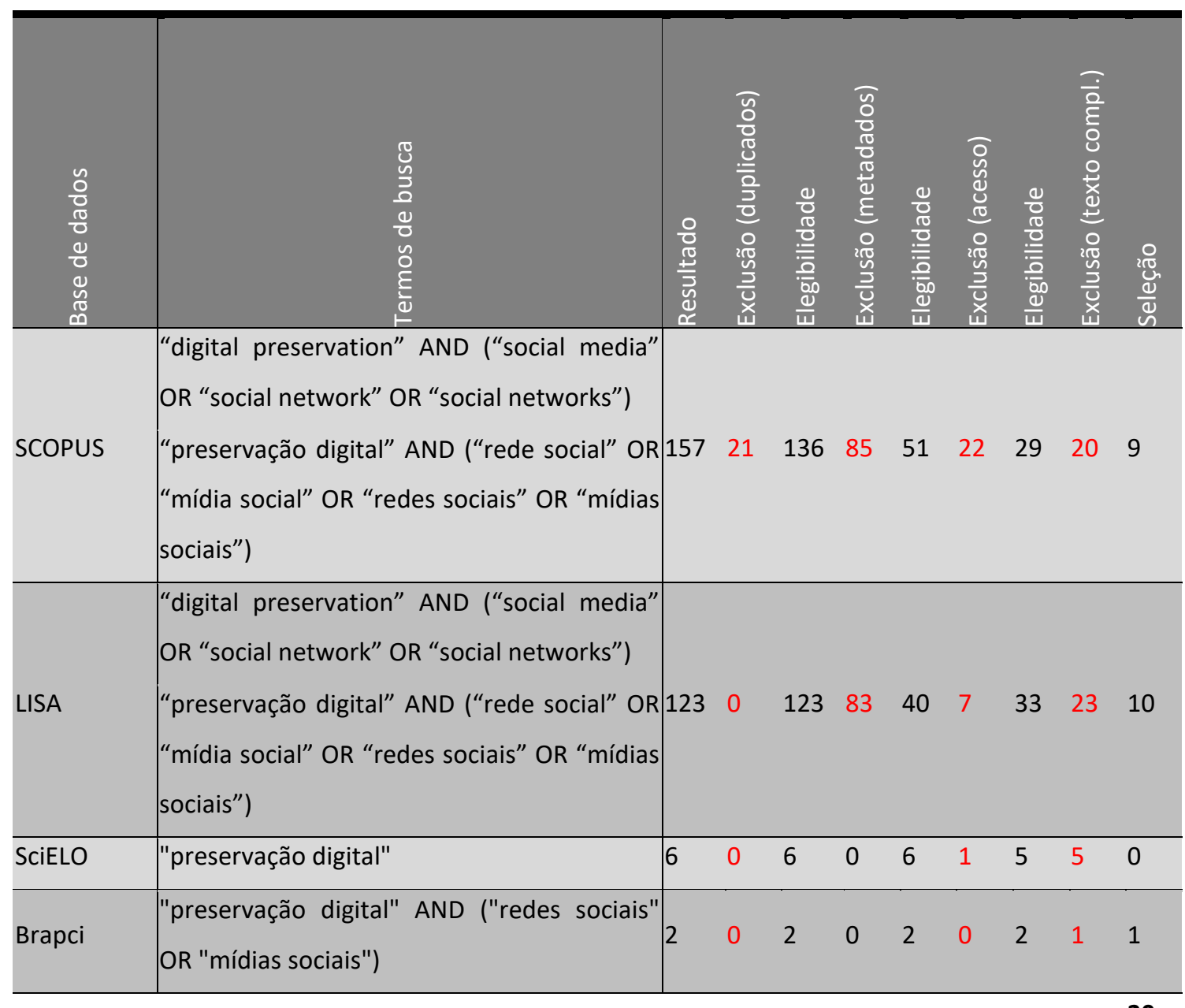

20

Fonte: Elaborada pelos autores (2018)

Das 123 publicações retornadas pela LISA, 83 foram descartadas com base nos metadados, 7 foram excluídas por impossibilidade de acesso e mais 23 foram eliminadas depois da leitura integral de seus respectivos textos. Assim, um total de $10[123-(83+7+23)]$ publicações foram selecionadas da base de dados LISA.

Nenhum dos 6 textos retornados pela SciELO foi selecionado. Uma publicação retornada pela Brapci foi selecionada após a leitura de seu texto na íntegra. Assim, um total de $20(9+10+0+1)$ publicações foram selecionadas para esta revisão sistemática de literatura.

\section{Descrição e análise dos achados}

O Quadro 1 reúne os 20 artigos selecionados para esta revisão sistemática de literatura, conforme descrito na metodologia. Ao observar os anos de publicação dos artigos, é possível perceber que, ao contrário do que se esperava para a temática abordada supostamente em constante atualização e cada vez mais em evidência em virtude do seu 
cunho tecnológico -,a amostra não revelou um crescimento significativo no número de publicações ao longo dos anos. De fato, de acordo com o Quadro 1, o maior número de publicações aconteceu em 2016. Ressalta-se que, mesmo considerando o recorte temporal da seleção dos artigos - até julho de 2018, um pouco mais que metade do ano -, a pesquisa registrou apenas 2 publicações para esse período, o que representa $1 / 3$ do total publicado em 2016.

Quadro 1 - Publicações incluídas nesta RSL

\begin{tabular}{|c|c|c|c|}
\hline $\begin{array}{l}\text { Ano de } \\
\text { Publicação }\end{array}$ & Título & Autores(as) & Fonte de Publicação \\
\hline 2018 & $\begin{array}{l}\text { A twitter case study for assessing digital } \\
\text { sound }\end{array}$ & Giannetti, F. & $\begin{array}{l}\text { Journal of the Association } \\
\text { for Information Science and } \\
\text { Technology }\end{array}$ \\
\hline 2018 & $\begin{array}{l}\text { API-based social media collecting as a } \\
\text { form of web archiving }\end{array}$ & $\begin{array}{l}\text { Littman, J.; Chudnov, } \\
\text { D.; Kerchner, D.; } \\
\text { Peterson, C.; Tan, Y.; } \\
\text { Trent, R.; Vij, R.; } \\
\text { Wrubel, L. }\end{array}$ & $\begin{array}{l}\text { International Journal on } \\
\text { Digital Libraries }\end{array}$ \\
\hline 2017 & $\begin{array}{l}\text { Tweets may be archived: Civic } \\
\text { engagement, digital preservation and } \\
\text { Obama White House social media data }\end{array}$ & Acker, A.; Kriesberg, A. & $\begin{array}{l}\text { Proceedings of the } \\
\text { Association for Information } \\
\text { Science and Technology }\end{array}$ \\
\hline 2017 & $\begin{array}{l}\text { Community Archives in the Digital Era: A } \\
\text { Case from the LGBT Community }\end{array}$ & Cocciolo, A. & $\begin{array}{l}\text { Preservation, Digital } \\
\text { Technology \& Culture }\end{array}$ \\
\hline 2017 & $\begin{array}{l}\text { Managing Digital Cultural Objects: } \\
\text { Analysis, Discovery, and Retrieval }\end{array}$ & Washington, A. & $\begin{array}{l}\text { Library Resources \& } \\
\text { Technical Services }\end{array}$ \\
\hline 2017 & The evolution of web archiving & $\begin{array}{l}\text { Costa, M.; Gomes, D.; } \\
\text { Silva,_J. M. }\end{array}$ & $\begin{array}{l}\text { International Journal on } \\
\text { Digital Libraries }\end{array}$ \\
\hline 2016 & Preservation challenges in the digital age & Houghton, B. & D-Lib Magazine \\
\hline 2016 & $\begin{array}{l}\text { Toward a rational and sustainable } \\
\text { division of labor for the preservation of } \\
\text { knowledge }\end{array}$ & Reilly, B. F. & Library Management \\
\hline 2016 & $\begin{array}{l}\text { Digital curation beyond the "wild } \\
\text { frontier": a pragmatic approach }\end{array}$ & Dallas, C. & Archival Science \\
\hline 2016 & $\begin{array}{l}\text { How are the new documents of social } \\
\text { networks shaping our cultural memory }\end{array}$ & $\begin{array}{l}\text { Henninger, } \\
\text { Scifleet, } P \text {. }\end{array}$ & Journal of Documentation \\
\hline 2016 & $\begin{array}{l}\text { Preventing sensitive relationships } \\
\text { disclosure for better social media }\end{array}$ & $\begin{array}{l}\text { Raad, E.; Al Bouna, B.; } \\
\text { Chbeir, R. }\end{array}$ & $\begin{array}{l}\text { International Journal of } \\
\text { Information Security }\end{array}$ \\
\hline
\end{tabular}




\begin{tabular}{|c|c|c|c|}
\hline & preservation & & \\
\hline 2016 & $\begin{array}{l}\text { Mídias Sociais Em Tempos De Bibliotecas } \\
\text { 2.0: Um Estudo Em Bibliotecas Das } \\
\text { Instituições Federais De Ensino } \\
\text { Brasileiras Trazendo Perspectivas Futuras } \\
\text { Para A Preservação Digital }\end{array}$ & $\begin{array}{l}\text { Rezende, L. V. R.; } \\
\text { Martins, D. L.; Silva } \\
\text { Ferrante, M. }\end{array}$ & $\begin{array}{l}\text { RDBCl: Revista Digital de } \\
\text { Biblioteconomia e Ciência } \\
\text { da Informação }\end{array}$ \\
\hline 2015 & $\begin{array}{l}\text { Acquisition and preservation of authentic } \\
\text { information in a digital age }\end{array}$ & $\begin{array}{l}\text { Hajtnik, T.; Uglesic, K.; } \\
\text { Zivkovic, A. }\end{array}$ & Public Relations Review \\
\hline 2015 & $\begin{array}{l}\text { Public Library: A Place for the Digital } \\
\text { Community Archive }\end{array}$ & Copeland, A. & $\begin{array}{l}\text { Preservation, Digital } \\
\text { Technology \& Culture }\end{array}$ \\
\hline 2015 & $\begin{array}{l}\text { Social Media in Archives and Libraries: A } \\
\text { Snapshot of Planning, Evaluation, and } \\
\text { Preservation Decisions }\end{array}$ & $\begin{array}{l}\text { Liew, C. L.; King, V.; } \\
\text { Oliver, G. }\end{array}$ & $\begin{array}{l}\text { Preservation, Digital } \\
\text { Technology \& Culture }\end{array}$ \\
\hline 2015 & $\begin{array}{l}\text { A scalable approach to harvest modern } \\
\text { weblogs }\end{array}$ & $\begin{array}{l}\text { Banos, V.; Blanvillain, } \\
\text { O.; Kasioumis, N.; } \\
\text { Manolopoulos, Y. }\end{array}$ & $\begin{array}{l}\text { International Journal on } \\
\text { Artificial Intelligence Tools }\end{array}$ \\
\hline 2015 & $\begin{array}{l}\text { Preserving Social Media: The Problem of } \\
\text { Access }\end{array}$ & $\begin{array}{l}\text { Thomson, S. D.; } \\
\text { Kilbride, W. }\end{array}$ & $\begin{array}{l}\text { New Review of Information } \\
\text { Networking }\end{array}$ \\
\hline 2014 & $\begin{array}{l}\text { Personal documentation on a social } \\
\text { network site: Facebook, a collection of } \\
\text { moments from your life? }\end{array}$ & Sinn, D.; Syn, S. Y. & Archival Science \\
\hline 2014 & $\begin{array}{l}\text { Towards building a blog preservation } \\
\text { platform }\end{array}$ & $\begin{array}{l}\text { Kasioumis, N.; Banos, } \\
\text { V.; Kalb, H. }\end{array}$ & World Wide Web \\
\hline 2013 & $\begin{array}{l}\text { Towards preservation of semantically } \\
\text { enriched architectural knowledge }\end{array}$ & $\begin{array}{lr}\text { Dietze, S.; Beetz, J.; } \\
\text { Gadiraju, } \\
\text { Katsimpras, } \\
\text { Wessel, R.; }\end{array}$ & $\begin{array}{l}\text { CEUR } \\
\text { Proceedings }\end{array}$ \\
\hline
\end{tabular}

Fonte: Elaborado pelos autores (2018)

No que concerne às autorias, verificou-se que, para a temática "preservação digital em mídias sociais", as pesquisas colaborativas são mais frequentes do que as de autoria isolada. Das 20 publicações, como pode ser visto no Quadro 1, sete foram publicadas por apenas um autor(a), e as outras 13 foram publicadas em colaboração, ou seja, por pelo menos dois autores(as). Essa discrepância, embora pequena, pode ser explicada pela relação interdisciplinar e fronteiriça dessa temática. Ainda em relação à autoria dessas publicações, observa-se que apenas dois nomes de pesquisadores, dos 49 revelados pela RSL nos 20 artigos selecionados, se repetem: Banos e Kasioumis, que foram coautores dos artigos " $A$ scalable 
approach to harvest modern weblogs", de 2015, e "Towards building a blog preservation platform", de 2014.

O Quadro 1 evidencia, ainda, uma grande diversidade quanto às fontes de publicação, pois os 20 artigos foram publicados em 16 periódicos diferentes, como pode ser visualizado no Gráfico 1.A diversidade apresentada pelo Gráfico 1 aponta que apenas três revistas publicaram mais de um artigo sobre a temática desta RSL: a Preservation, Digital Technology \& Culture, com três publicações, e a International Journal on Digital Libraries e a Archival Science, com duas publicações cada. A heterogeneidade dos autores e das fontes de publicação corroboram a ideia de interdisciplinaridade e tema de fronteira exposta anteriormente. Essas são características que podem reforçar, além disso, o quanto o tema abordado é recente e as pesquisas a ele relacionadas representam uma lacuna na literatura acadêmica. Isso porque, ao estudar temas consolidados na literatura, é comum perceber que alguns autores e fontes de publicação se destacam como referência, o que ainda não acontece quando se trata de preservação digital em mídias sociais.

Gráfico 1 - Diversidade das fontes de publicação

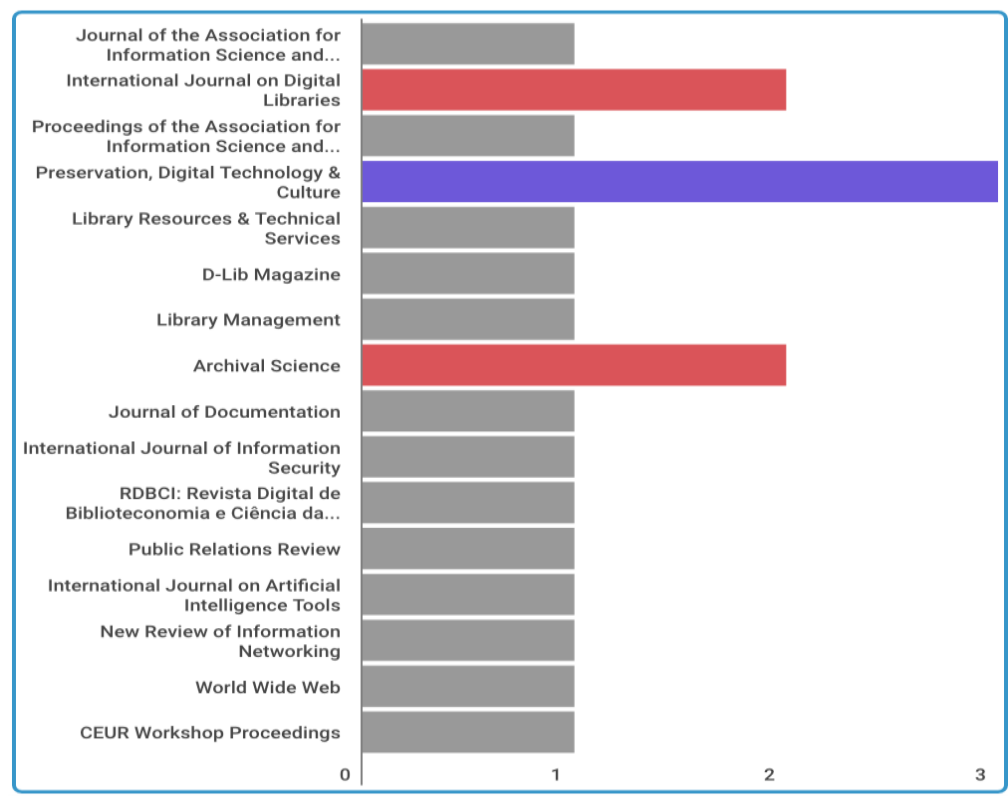

Fonte: Elaborado pelos autores (2018)

No que diz respeito às palavras-chave,as publicações selecionadas usaram 71 expressões, as quais tiveram um papel fundamental na fase de elegibilidade desta RSL. A Figura 1 representa o grau de frequência das palavras-chave em forma de nuvem de tags. Quanto maior a frequência da palavra-chave, maior sua representatividade na imagem.Entre as 71 palavras-chave, as que mais se destacaram foram: "Digital Preservation", com seis 
ocorrências; "Social Media", com 4 ocorrências; "WEB Archiving", com 3 ocorrências; e "Social Media Preservation", "Social Networks" e "Data Collection", com duas ocorrências cada. Todas as demais palavras-chave tiveram apenas uma única ocorrência nos artigos selecionados. Ou seja, mesmo os termos utilizados para abordar a preservação digital em mídias sociais parecem não estar estabelecidos e consolidados entre os pesquisadores.

Figura 1 - Representação das palavras-chave em forma de nuvem de tags

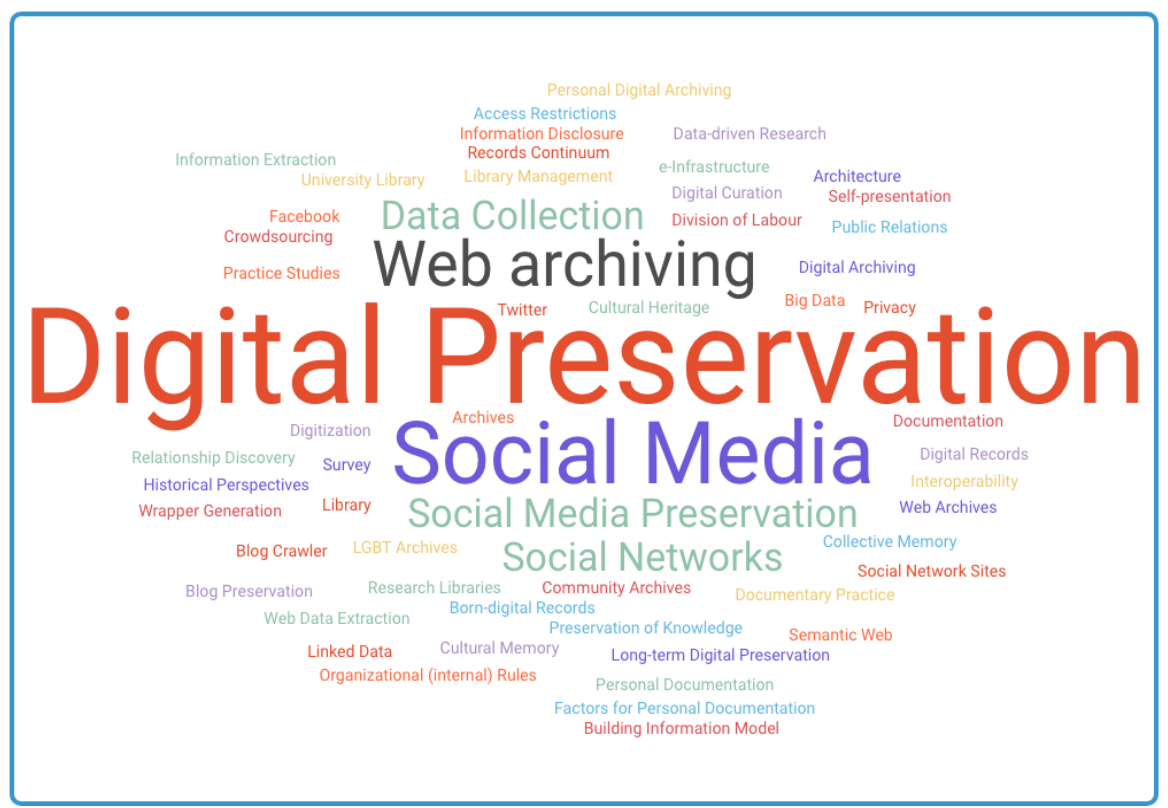

Fonte: Elaborada pelos autores (2018)

Ressalta-se que todas as palavras-chave estão na Língua Inglesa, tendo em vista que 19 dos 20 artigos foram escritos em inglês. Apenas o artigo de 2016 intitulado "Mídias Sociais Em Tempos De Bibliotecas 2.0: um estudo em bibliotecas das instituições federais de ensino brasileiras trazendo perspectivas futuras para a preservação digital", dos autores Rezende, Martins e Silva, foi escrito em português. Para este artigo, as keywords do abstract foram utilizadas. Vale ressaltar, também, que nenhuma das fontes de publicação é brasileira.

\section{Discussão acerca da preservação digital em mídias sociais}

Esse estudo proporcionou a identificação de tópicos-chave, utilizados nesta Seção para facilitar o entendimento da análise qualitativa dos textos, são eles: 1) conceitos, 2) importância, 3) desafios e 4) estratégias. Desse modo, cada um desses elementos e a forma pela qual eles são abordados nas publicações que compõem esta RSL serão apresentados nas subseções a seguir. 


\subsection{Conceitos}

As publicações selecionadas nesta RSL não definiram de forma explícita ou concreta o que seria "preservação digital em mídias sociais". No entanto, expuseram características e especificidades relacionadas ao tema. Observou-se nos artigos - com apenas duas exceções a linguagem direta e objetiva e a falta de definições precisas, pressupondo conhecimento prévio do leitor sobre conceitos-chave relacionados à temática. De fato, essa falta de conceitualizações precisas foi notadamente uma característica em comum encontrada nos textos.As exceções são os artigos de Dallas (2016, p. 421, tradução nossa), que defende a necessidade de alternativas ao paradigma custodial da curadoria digital como um "conceito guarda-chuva para preservação digital, curadoria de dados, registros eletrônicos e gerenciamento de ativos digitais", e de Rezende et. al. (2016), cuja pesquisa realizou um levantamento de caráter quantitativo acerca do uso das principais mídias sociais existentes por parte das bibliotecas das IFES brasileiras. Esses dois artigos fazem uso de um aporte teórico mais aprofundado, antes de seguirem seus respectivos objetivos.Um fato que merece destaque é que dessas duas publicações que trazem um aporte teórico mais aprofundado, uma é justamente a única escrita em Língua Portuguesa: Rezende et al. (2016).

Seis termos relacionados a essa temática de preservação digital em mídias sociais, contudo, foram conceituados nas publicações que compõem esta RSL: arquivamento da Web, coleta em mídia social, mídia social, preservação digital, rede social e Web 2.0. Tais termos estão listados no Quadro 2.

Quadro 2 - Conceitos de termos relacionados à preservação digital em mídias sociais identificados na RSL

\begin{tabular}{|l|l|l|l|}
\hline \multicolumn{2}{|c|}{ Referência } & \multicolumn{2}{l|}{ Conceitos } \\
\hline $\begin{array}{l}\text { Littman et al. } \\
(2018)\end{array}$ & $\begin{array}{l}\text { Arquivamento } \\
\text { da Web }\end{array}$ & $\begin{array}{l}\text { Processo de coleta dos dados que foram publicados na Web. } \\
\text { Armazenamento, preservação e disponibilização para pesquisas } \\
\text { futuras. }\end{array}$ \\
\hline $\begin{array}{l}\text { Littman et al. } \\
(2018)\end{array}$ & $\begin{array}{l}\text { Coleta em } \\
\text { mídia social }\end{array}$ & $\begin{array}{l}\text { Recuperar e armazenar conteúdo de mídia social das interfaces de } \\
\text { programação de aplicativos (APIs) de plataformas de mídia social. } \\
\text { Um tipo de arquivamento da Web. }\end{array}$ \\
\hline $\begin{array}{l}\text { Acker e Kriesberg } \\
(2017)\end{array}$ & Mídia Social & $\begin{array}{l}\text { Dados de mídia social são uma nova forma de evidência do } \\
\text { comportamento online. Para os pesquisadores, não apenas } \\
\text { representa um novo objeto de estudo, mas uma nova forma de } \\
\text { instrumentação para coletar dados sobre o comportamento de } \\
\text { pessoas, redes formas contemporâneas de comunicação. }\end{array}$ \\
\hline $\begin{array}{l}\text { Rezende et al. } \\
\text { (2016) }\end{array}$ & Mídia Social & $\begin{array}{l}\text { Mídias sociais são páginas da Web que possibilitam ao usuário atuar } \\
\text { não apenas como um mero leitor, e sim como produtor, curador e } \\
\text { consumidor da informação, com a liberdade de criar, recomendar e } \\
\text { trocar conteúdo com os outros usuários (TORRES, 2009). }\end{array}$ \\
\hline $\begin{array}{l}\text { Thomson e Kilbride } \\
(2015)\end{array}$ & Mídia Social & $\begin{array}{l}\text { Espaços amplamente utilizados para as comunidades interagirem e } \\
\text { compartilharem informações em todo o mundo. }\end{array}$ \\
\hline
\end{tabular}




\begin{tabular}{|c|c|c|}
\hline Dallas (2016) & $\begin{array}{l}\text { Preservação } \\
\text { Digital }\end{array}$ & $\begin{array}{l}\text { Série de atividades gerenciadas necessárias para garantir o acesso } \\
\text { contínuo a materiais digitais pelo tempo que for necessário (JONES; } \\
\text { BEAGRIE, 2001) }\end{array}$ \\
\hline $\begin{array}{l}\text { Rezende } \\
(2016)\end{array}$ & $\begin{array}{l}\text { Preservação } \\
\text { Digital }\end{array}$ & $\begin{array}{l}\text { Combina políticas, estratégias e ações que garantem acesso a } \\
\text { conteúdos nativos digitais ou digitalizados independentemente dos } \\
\text { desafios relacionados a falhas de arquivos, mídias ou mudanças } \\
\text { tecnológicas. Visa garantir autenticidade do documento ao longo do } \\
\text { tempo. } \\
\text { Pode ser entendida como o conjunto de atividades ou processos } \\
\text { responsáveis por garantir o acesso continuado a longo prazo à } \\
\text { informação e ao patrimônio cultural existentes em formatos digitais. }\end{array}$ \\
\hline Washington (2017) & $\begin{array}{l}\text { Preservação } \\
\text { Digital }\end{array}$ & $\begin{array}{l}\text { É a chave para a recuperação de objetos digitais culturais e nos } \\
\text { últimos anos tem crescido em estudo e prática. }\end{array}$ \\
\hline Raad et al. (2016) & Rede Social & $\begin{array}{l}\text { É o compartilhamento de informações. É uma das formas mais } \\
\text { comuns de interação online e que está intimamente associada à } \\
\text { preservação da mídia social e divulgação de informações. }\end{array}$ \\
\hline $\begin{array}{l}\text { Rezende et al. } \\
(2016)\end{array}$ & Rede Social & $\begin{array}{l}\text { Ambiente online no qual um usuário pode estabelecer relações com } \\
\text { outros usuários que tenham alguma ligação e/ou interesse em } \\
\text { comum. }\end{array}$ \\
\hline $\begin{array}{l}\text { Rezende } \\
\text { (2016) }\end{array}$ & Web 2.0 & $\begin{array}{l}\text { Conjunto de novas tecnologias e padrões para desenvolvimento de } \\
\text { páginas interativas na Internet que disponibilizam recursos para que } \\
\text { os usuários possam publicar conteúdos e interagir, como por } \\
\text { exemplo, curtir, compartilhar, comentar, com objetos dessas } \\
\text { páginas. } \\
\text { Segunda geração da Web projetada para facilitar as relações sociais, } \\
\text { o compartilhamento da informação, a interoperabilidade e a } \\
\text { comunicação (TRIPATHI; KUMAR, 2010). }\end{array}$ \\
\hline
\end{tabular}

Fonte: Elaborado pelos autores(2018)

Observando o Quadro 2, é possível perceber que os conceitos apresentados são abrangentes, genéricos, sem grandes detalhamentos ou divergências entre os autores. Além disso, apesar de não haver uma definição precisa de preservação digital em mídias sociais, esses conceitos vem sendo definidos separadamente e relacionados nos artigos.

\subsection{Importância}

As mídias sociais se tornaram espaços amplamente utilizados pelas comunidades mais diversas para interagirem e compartilharem informações. Nelas, todos podem publicar quaisquer tipos de dados e utilizar os mais variados tipos de mídia. À medida que essas comunidades crescem e o número de usuários aumenta, elas deixam para trás um valioso registro cultural e histórico (COSTA et al., 2017) da nossa sociedade. Por isso, discutir a importância da preservação digital em mídias sociais é falar sobre a importância do conteúdo gerado por seus usuários para a sociedade. De acordo com Littman et al. (2018), os dados advindos das mídias sociais são utilizados ampla e ativamente pela comunidade científica e acadêmica, comunidade jurídica, jornalistas, agências governamentais, defensores do governo 
aberto e outros pesquisadores "não acadêmicos". Ainda segundo esses autores, de maneira análoga à comunidade acadêmica, esses pesquisadores "não acadêmicos" enfrentam desafios ao usar coleções de dados de mídia social que não possuem documentação apropriada sobre como foram coletados e gerenciados ao longo do tempo. Além disso, a velocidade e dinamicidade da produção e compartilhamento de informações nas mídias sociais provoca perda constante de dados.

Costa et al. (2017) citam estudos que apontam perdas de dados na Web: $13 \%$ das referências a artigos científicos desaparecem após 27 meses; 11\% dos recursos de mídia social, como os post no Twitter, são perdidos após 1 ano. Segundo esses autores, informações desse tipo tendem a desaparecer em poucos anos, criando uma lacuna de conhecimento sobre o presente para as futuras gerações. Thomson e Kilbride (2015) também comentam sobre a remoção e edição de tweets.

Segundo Giannetti (2018), pesquisadores demonstraram que as produções de humanidades têm uma alta densidade de menções à mídia social por trabalho, e que a pesquisa em humanidades geralmente obtém mais referências nas mídias sociais do que nos registros acadêmicos. A pesquisa em mídias sociais, que muda o foco dos objetos para as interações, modela abordagens etnográficas para o estudo das comunidades online. $O$ estudo dessas interações permite ao pesquisador considerar motivações do usuário e fatores socioculturais, o que pode ajudar a contextualizar referências a objetos patrimoniais digitais.

Adicionalmente, Hajtnik et al. (2015) afirmam que é comum que registros de mídia social sirvam de fontes de evidências em processos criminais e civis, o que reforça a necessidade de preservação. Os autores afirmam, ainda, que uma certa parte dos registros feitos nas mídias sociais também são avaliados como registros arquivísticos, que constituem a herança cultural de uma nação.

\subsection{Desafios}

A preservação digital em mídias sociais possui inúmeros desafios, o que a torna um problema que necessita de constante reavaliação. Há obstáculos apresentados pelos interesses comerciais das plataformas de mídia social,e é preciso levar em consideração a natureza sensível do conteúdo gerado pelos seus usuários. Houghton (2016) discute os principais desafios na preservação digital, de forma geral, e abrange uma série de aspectos técnicos, administrativos, legais e logísticos. Já Thomson e Kilbride (2015) se dedicaram exclusivamente ao desafio do acesso aos dados em mídias digitais.

Assim, de forma resumida, os desafios mais explorados pelas publicações desta RSL são: 
- ter acesso ao conteúdo a ser preservado - para que seja possível preservar um conteúdo, é necessário ter acesso a ele, o que nem sempre ocorre na prática;

- volume dos dados a serem preservados - quanto maior o volume dos dados, maior é a complexidade na preservação;

- formato de arquivo -nem todos os formatos de arquivos encontrados nas mídias sociais são ideais para preservação;

- custo - preservação digital envolve custos, assim como não preservar também;

- questões éticas - dados preservados de mídias sociais podem revelar, intencionalmente ou não, informações pessoais sobre usuários;

- legalidade - leis podem aplicar restrições ao conteúdo que se deseja preservar;

- metadados mal especificados ou inexistentes -o que pode causar a irrecuperabilidade do conteúdo ou a dificuldade para conseguir recuperá-lo;

- restrições de privacidade -o que requer um controle maior daquilo que pode ou não ser preservado;

- necessidade de seleção -a questão de relevância do conteúdo a preservar deve ser levada em conta, a fim de determinar aquilo que deve ou não ser preservado, pois não é possível, a um custo razoável, preservar o grande volume de dados das mídias sociais;

- obsolescência tecnológica -hardware e software necessitam de manutenção e atualização periódicas.

Vale destacar o quão relacionados estes desafios estão. Por exemplo, solucionar um problema de obsolescência tecnológica pode impactar diretamente nos custos relacionados. A necessidade de seleção tem relação direta com o volume de dados a ser preservado etc. A Figura 2 ilustra o relacionamento entre esses desafios: 
Figura 2 - Relacionamento entre os desafios mais explorados pelas publicações desta RSL

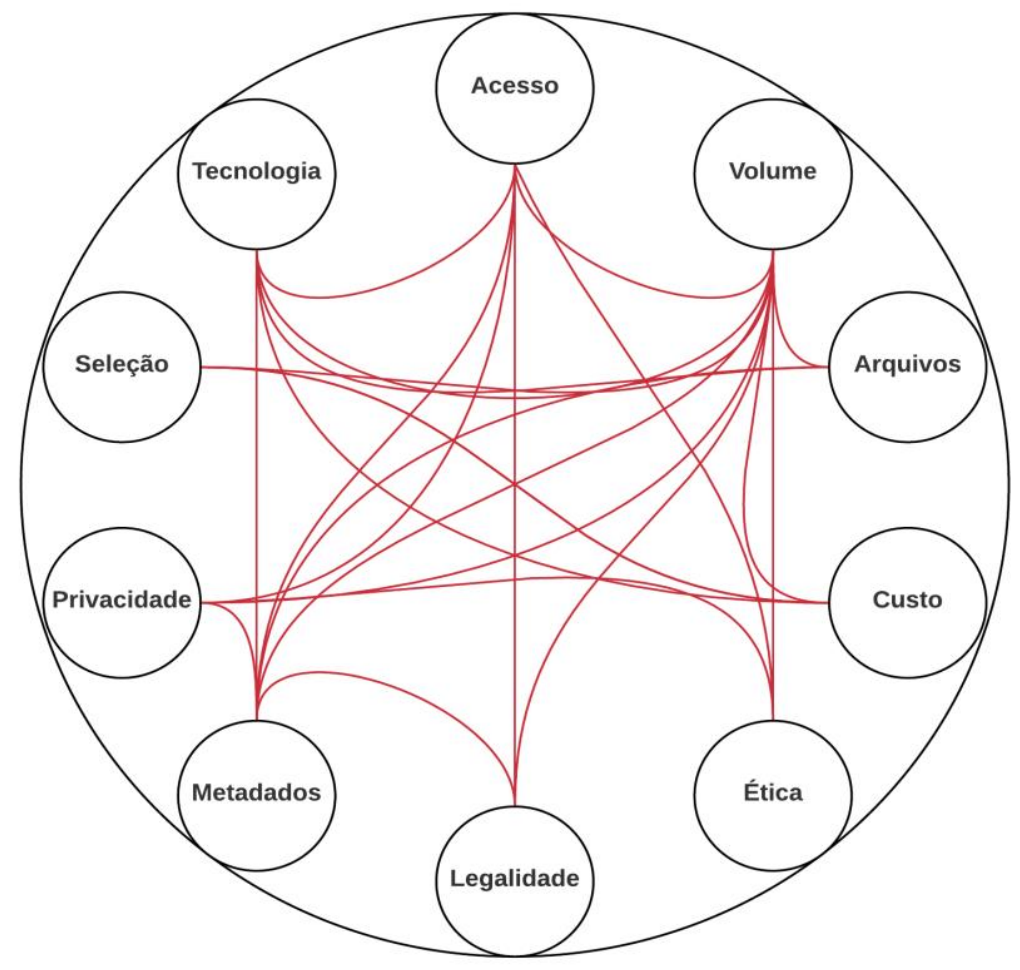

Fonte: Elaborada pelos autores (2018).

O desafio do acesso está fortemente ligado aos desafios legais, de privacidade e éticos e à obsolescência das tecnologias envolvidas, seja o software escolhido ou o hardware utilizado. Segundo Thomson e Kilbride (2015), o acesso, a aquisição ou a captura de dados para uso, processamento e compartilhamento pode ser impedido por bloqueios tecnológicos, curatoriais, legais e/ou éticos. As leis, por exemplo, necessitam de tempo para acompanhar os avanços tecnológicos e podem variar de acordo com o país em questão. Segundo Houghton (2016), na maioria dos casos, os dados digitais ficam sujeitos a algum nível de restrição. Leis podem aplicar restrições à cópia, ao armazenamento, ao acesso, à edição de conteúdo, assim como ao seu uso ou reutilização.

O conteúdo escolhido para preservação pode conter informações privadas e confidenciais, e sua liberação não autorizada pode levar a ações legais. Sobre privacidade em mídias sociais, Houghton (2016) destaca que é uma suposição justa dizer que boa parte dos usuários que se comunicam online não têm consciência de quão difundidas e públicas suas comunicações podem se tornar. Para Raad et al. (2016), a preservação aplicada a mídias sociais deve se alinhar às soluções de privacidade e, consequentemente, proteger informações confidenciais que os usuários de redes sociais gostariam de manter confidenciais. 
Segundo Sinn e Syn (2014), privacidade e preocupações éticas prejudicam ainda mais os esforços de instituições em coletar dados de redes sociais. Por outro lado, Thomson e Kilbride (2015) destacam que instituições de coleta têm a responsabilidade ética de proteger os indivíduos representados nos dados, proteção essa que mesmo o anonimato pode não garantir.

Para Houghton (2016), um dos desafios mais fundamentais da preservação é a seleção, ou seja, determinar o que deve ser preservado. Segundo o autor, não é viável preservar tudo. Por outro lado, a prática de preservar mídias sociais requer métodos interativos e vinculantes. Por exemplo, preservar os posts de um usuário particular é entender apenas um lado da conversa. Para Costa et al. (2017), como os recursos são escassos, a política de seleção da maioria das iniciativas de arquivamento na Web é de preservar as partes mais relevantes, a partir de sua própria perspectiva. Isso dá a entender que alguém ou algum dispositivo tecnológico vai delimitar, por exemplo, o início e o fim de uma conversa numa rede social.

Note que os desafios de seleção e de custo também estão conectados. Segundo Houghton (2016), a escolha de não preservar também envolve custos, não apenas na possível perda de dados valiosos mas também na herança cultural. Por um lado, preservar tudo é muito caro, requer muito recurso financeiro e tecnológico. Em contrapartida, a seleção inadequada ou equivocada do que deve ou não ser preservado pode sair mais cara ainda.

Os metadados são informações estruturadas que descrevem, explicam, localizam ou, de alguma forma, facilitam a recuperação, o uso ou o gerenciamento dos dados. Segundo Houghton (2016), os metadados são, provavelmente, o aspecto mais importante da preservação digital, pois, se incompletos ou desestruturados, podem tornar os conteúdos irrecuperáveis, ter sua autenticidade não verificável e seu contexto incompreensível. Além disso,os metadados podem mudar conforme a tecnologia avança e as plataformas de software usadas para entregá-los e apresentá-los evoluem (REILLY, 2016).

Para Acker e Kriesberg (2017), embora os dados de mídia social possam ser extraídos usando interfaces de programação de aplicativos e, às vezes, extraídos da Web, camadas de metadados, particularmente relacionadas ao engajamento (as mesmas atividades que tornam os dados de mídia social "sociais"), são geralmente incompletas ou sujeitas a termos de serviço, gerenciamento de dados e políticas de armazenamento.

O formato de um arquivo é um modo específico de codificar os dados para o seu armazenamento e já foi considerado um grande risco à preservação digital (HOUGHTON, 2016). Atualmente, com os formatos abertos de arquivo, esse desafio se tornou menos preocupante. Um arquivo de formato aberto, em oposição ao de formato fechado ou proprietário, é um arquivo acessível a todos e sem bloqueios legais. Entretanto, os arquivos 
em formatos proprietários podem se tornar um grande desafio à preservação digital, pois, de acordo com Houghton (2016), suas especificações são menos propensas a estarem disponíveis abertamente. Tornar o software compatível com esses formatos ou converter os próprios arquivos em um formato aberto só pode ser feito com a permissão do detentor da patente.

Por fim, em um mundo cada vez mais digital, o imenso volume de dados armazenado se torna um desafio para a preservação digital. Esse desafio, do armazenamento, impacta a todos os outros, uma vez que quanto maior a quantidade de dados, maior a complexidade nas escolhas para preservação.

\subsection{Estratégias}

De acordo com a leitura dos textos selecionados, as principais estratégias usadas na preservação digital de mídias sociais estão associadas a alguma Application Programming Interface $(A P I)$. Uma $A P I$ constitui uma forma de integração entre sistemas ou plataformas digitais, que, entre outras coisas, permite o acesso seguro e facilita a troca de dados. No contexto das mídias sociais, uma $A P I$ atua como uma espécie de interface entre a plataforma de mídia social e seu consumidor.

As estratégias encontradas nos artigos foram: 1) fazer uso da API da plataforma; 2) negociar diretamente com a plataforma; 3 ) comprar os dados de revendedores ou usar um serviço comercial de terceiros (THOMSON, KILBRIDE, 2015; ACKER, KRIESBERG, 2017; COCCIOLO, 2017; LITTMAN et al., 2018). Note que, exceto quando a aquisição dos dados é feita diretamente com a plataforma de mídia social, todas as outras estratégias mencionadas usam alguma $A P I$.

Segundo Thomson e Kilbride (2015), a não ser que uma negociação direta com a plataforma de mídia social seja possível, a maneira mais eficaz e econômica de acessar dados de mídias digitais é por intermédio de uma API. Os autores afirmam ainda que, para os propósitos da ciência social baseada em dados - data-driven social Science -, as únicas soluções reais de coleta de dados se dão por intermédio de APIs ou aquisição direta.

De acordo com Acker e Kriesberg (2017), os dados coletados por intermédio de APIs possuem metadados incompletos e sujeitos a termos de serviço e/ou políticas de armazenamento que limitam o compartilhamento, a coleta e o uso desses dados, dificultando, por exemplo, a replicação de um experimento ou a comparação de publicações ao longo do tempo. Analogamente, Thomson e Kilbride (2015) afirmam que a maioria das plataformas de mídia social, como as do Facebook e Twitter, que fornecem acesso às suas APIs, restringe a quantidade de dados que podem ser solicitados. Essa realidade ilustra a complexidade dessa 
discussão e levanta questionamentos quanto à confiabilidade de pesquisas e análises que fazem uso desses conjuntos de dados.

\section{Considerações finais}

A realização deste trabalho ajudou na percepção de um sinal de dissonância entre as pesquisas sobre preservação digital em mídias sociais no Brasil e no mundo. Também ajudou a perceber, como suposto, que essa é uma temática de fronteira, interdisciplinar e que possui literatura escassa e predominantemente em língua inglesa.

A RSL elaborada permitiu identificar conceitos, demonstrar a importância da preservação de dados advindos de mídias sociais, reunir, relacionar e descrever seus desafios e, por fim, discutir as principais estratégias relacionadas à temática.Os desafios enfrentados na preservação digital em mídias sociais foi o tópico mais discutido pelos autores nos 20 textos selecionados. Isso se dá pela característica mutante das tecnologias que sustentam as plataformas de mídia social. Elas atualizam seus termos e condições de uso com tanta frequência que as APIs desenvolvidas para interagir com esses dados se tornam restritas ou ineficientes em apenas alguns anos.

À medida que as plataformas, governos e instituições de pesquisa e coleta desenvolvem leis, políticas e estratégias para preservação do conteúdo armazenado nas bases de dados das mídias sociais, a avaliação das necessidades e expectativas do usuário ajudará a orientar as decisões sobre o que preservar, o quanto e de que forma, suavizando os desafios e melhorando as estratégias.

Por fim, é importante destacar que, embora as bases de dados escolhidas para a seleção das publicações sejam multidisciplinares e de grande representatividade acadêmica em nível mundial, um número significativo de artigos não pôde ser analisado por restrições de acesso. Além disso, sentiu-se, ao decorrer das análises, que outras fontes de publicações deveriam ser incluídas com o intuito de reforçar as evidências que foram encontradas. Por vezes, organizações que discutem preservação digital foram citadas pelos autores; a Digital Preservation Coalition (DPC), por exemplo, indica a leitura de alguns artigos que, certamente,satisfazem os critérios de inclusão desta RSL.

\section{Referências}

ACKER, A.; KRIESBERG, A. Tweets May Be Archived: Civic Engagement, Digital Preservation and Obama White House Social Media Data. Association for Information Science \& Technology, Washington, v. 54, n. 1, 2017. Disponível em: <https://onlinelibrarywiley.ez15.periodicos.capes.gov.br/doi/epdf/10.1002/pra2.2017.14505401001>. Acesso em: 10 abr. 2019. 
COCCIOLO, A. Community Archives in the Digital Era: A Case from the LGBT Community. Preservation, Digital Technology \& Culture, Berlin, v. 45, n. 4, p. 157-165, 2017. Disponível em: $\quad<$ https://searchproquest.ez15. periodicos.capes.gov.br/lisa/docview/1868026257/fulltextPDF/AB3E80D8F9CC 4A5APQ/1?accountid=26611>. Acesso em: 10 abr. 2019.

COSTA, M.; GOMES, D.; SILVA, M. J. The evolution of web archiving. International Journal of Digital Libraries, v. 18, n. 3, p. 191-205, 2017. Disponível em: <https://link-springercom.ez15.periodicos.capes.gov.br/content/pdf/10.1007\%2Fs00799-016-0171-9.pdf >. Acesso em: 10 abr. 2019.

DALLAS, C. Digital curation beyond the "wild frontier": a pragmatic approach. Archival Science, Dordrecht, v. 16, n. 4, p. 421-457, 2016. Disponível em: <https://searchproquest.ez15. periodicos.capes.gov.br/lisa/docview/1829707148/fulltextPDF/3D1188E826F14 CE1PQ/2 ? accountid=26611>. Acesso em: 10 abr. 2019.

FERREIRA, M. Introdução à Preservação digital: Conceitos, estratégias e actuais consensos. Guimarães, Portugal: Escola de Engenharia da Universidade do Minho, 2006. 85p. Disponível em: $<$ https://repositorium.sdum.uminho.pt/bitstream/1822/5820/1/livro.pdf >. Acesso em: 10 abr. 2019.

FROHMANN, B. O caráter social, material e público da informação. In: FUJITA, M. S.; MARTELETO, R. M.; LARA, M. G. (Org.). A dimensão epistemológica da Ciência da Informação e suas interfaces técnicas, políticas e institucionais nos processos de produção, acesso e disseminação da informação. São Paulo: Cultura Acadêmica; Marília: Fundepe, 2008. p. 19-34.

GIANNETTI, F. A twitter case study for assessing digital sound. Journal of the Association for Information Science and Technology, Hoboken, v. 69, n. 5, p. 687-699, 2018. Disponível em: $<$ https://onlinelibrary-wiley.ez15.periodicos.capes.gov.br/doi/full/10.1002/asi.23990>. Acesso em: 10 abr. 2019.

HAJTNIK, T. et al. Acquisition and preservation of authentic information in a digital age. Public Relations Review, v. 41, n. 2, p. 264-271, 2015. Disponível em: <https://ac-elscdn.ez15.periodicos.capes.gov.br/S0363811114001945/1-s2.0-S0363811114001945-

main.pdf?_tid=a26b12e7-c9c1-42d7-8e23-

5814bfff2c75\&acdnat=1534011387_26ab12386c560923f82993c3f25abe87>. Acesso em: 10 abr. 2019.

HALL, S. S. et al. Children Reading to Dogs: A Systematic Review of the Literature. Plos One, Estados Unidos, v. 11, n. 2, 2016. Disponível em: <http://web.b-ebscohostcom.ez15.periodicos.capes.gov.br/ehost/pdfviewer/pdfviewer?vid=1\&sid=ccf0674d-6a79-

4fe4-8789-bd403a556179\%40pdc-v-sessmgr05>. Acesso em: 10 abr. 2019.

HOUGHTON, B. Preservation Challenges in the Digital Age.D - Lib Magazine, Reston, v. 22, n. 7, p. 1, jul. 2016. Disponível em: <http://www.dlib.org/dlib/july16/houghton/07houghton.html>. Acesso em: 10 abr. 2019.

JONES, M.; BEAGRIE, N. Preservation management of digital materials: a handbook. London: British Library, 2001.

LITTMAN, J. et al. API-based social media collecting as a form of web archiving. International 
Journal of Digital Libraries, v. 19, n. 1, p. 21-38, 2018. Disponível em: <https://link-springercom.ez15.periodicos.capes.gov.br/content/pdf/10.1007\%2Fs00799-016-0201-7.pdf>. Acesso em: 10 abr. 2019.

MIRANDA, R. C. R. Conhecimento Estratégico: Caracterização e Identificação Baseada em Revisão Sistemática e Bibliométrica. Informação \& Sociedade: Estudos, João Pessoa, v. 28, n. 1, p. 23-34, 2018. Disponível em: <http://www.periodicos.ufpb.br/ojs2/index.php/ies/article/view/30805>. Acesso em: 10 abr. 2019.

MOHER,D. et al. Preferred Reporting Items for Systematic Reviews and Meta-Analyses: The PRISMA Statement. PLOS Medicine, v. 6, n. 4, p. 1-6, 2009. Disponível em: $<$ http://journals.plos.org/plosmedicine/article/file?id=10.1371/journal.pmed.1000097\&type=p rintable>. Acesso em: 10 abr. 2019.

MUSSER, J; O'REILLY, T. Web 2.0 - Principles and best practices. Sebastopol, California: O'Reilly Media, 2007.

RAAD, E.; BECHARA, A. B.; CHBEIR, R. Preventing sensitive relationships disclosure for better social media preservation. International Journal of Information Security, v. 15, n. 2, p. 173194, 2016. Disponível em: <https://link-springercom.ez15.periodicos.capes.gov.br/content/pdf/10.1007\%2Fs10207-015-0278-9.pdf>. Acesso em: 3mai. 2019.

RECUERO, R. Redes Sociais na Internet. Porto Alegre: Sulina, 2009.

RECUERO, R. A nova revolução: as redes são as mensagens. In: BAMBRILLA, A. (Org.) Para entender as mídias sociais. [S.I] : [s.n], 2011. Disponível em: $<$ https://issuu.com/anabrambilla/docs/paraentenderasmidiassociais $>$. Acesso em: 3 mai. 2019.

REILLY, B. F. Toward a rational and sustainable division of labor for the preservation of knowledge. Library Management, Bradford, v. 37, n. 4, p. 166-169, 2016. Disponível em: $<$ https://search-

proquest.ez15. periodicos.capes.gov.br/lisa/docview/1799854043/7D838F5DDBD54093PQ/2?a ccountid=26611>. Acesso em: 10 abr. 2019.

REZENDE, L. V. R.; MARTINS, D. L.; SILVA, M. F. Mídias sociais em tempos de bibliotecas 2.0: um estudo em Bibliotecas das instituições federais de ensino brasileiras trazendo perspectivas futuras para a preservação digital. RDBCl: Revista Digital de Biblioteconomia e Ciência da Informação, Campinas-SP, v. 14, n. 3, p. 484-500, 2016. Disponível em: <https://periodicos.sbu.unicamp.br/ojs/index.php/rdbci/article/view/8646312>. Acesso em: 10 abr. 2019.

SINN, D.; SYN, S. Y. Personal documentation on a social network site: Facebook, a collection of moments from your life? Archival Science, v. 14, n. 2, p. 95-124, 2014. Disponível em: $<$ https://searchproquest.ez15. periodicos.capes.gov.br/lisa/docview/1524243202/fulltextPDF/8BA473FA7AA0 41C2PQ/1 ?accountid=26611>. Acesso em: 10 abr. 2019.

SOUSA, L. M. M.; AZEVEDO, L. E. O Uso de Mídias Sociais nas Empresas: adequação para cultura, identidade e públicos. In: CONGRESSO DE CIÊNCIAS DA COMUNICAÇÃO DA REGIÃO NORTE, 9., 2010, Rio Branco. Anais... Rio Branco: Intercom, 2010. Disponível em: 
$<$ www.intercom.org.br/papers/regionais/norte2010/resumos/R22-0015-1.pdf $>$. Acesso em: 10 abr. 2019.

TELLES, A. A revolução das mídias sociais: cases, conceitos, dicas e ferramentas. São Paulo: M. Books, 2010.

THOMSON, S. D.; KILBRIDE, W. Preserving Social Media: The Problem of Access. New Review of Information Networking, London, v. 20, n. 1-2, p. 261-275, May 2015. Disponível em: <http://content.ebscohost.com/ContentServer.asp?T=P\&P=AN\&K=111800052\&S=R\&D=aph\&E bscoContent=dGJyMNLe80Seprc4v\%2BvIOLCmr1Cep7dSs6m4Sq6WxWXS\&ContentCustomer= dGJyMOzpr1Guq69RuePfgeyx44Dt6fIA>. Acesso em: 10 abr. 2019.

TORRES, C. A bíblia do Marketing Digital: tudo o que você queria saber sobre o marketing e publicidade na internet e não tinha a quem perguntar. São Paulo: Novatec, 2009.

TRIPATHI, M.; KUMAR, S. Use of Web 2.0 tools in academic libraries: A reconnaissance of the international landscape. International Information \& Library Review, v. 42, n. 3, p. 195-207, 2010. <https://www.sciencedirect.com/science/article/abs/pii/S1057231710000445>. Acesso em: 10 abr. 2019.

WASHINGTON, A. Managing Digital Cultural Objects: Analysis, Discovery, and Retrieval. Library Resources \& Technical Services, Chicago, v. 61, n. 3, p. 175-176, 2017. Disponível em: $<$ https://searchproquest.ez15.periodicos.capes.gov.br/lisa/docview/1924499242/fulltextPDF/577911099DED 4E6CPO/1 ?accountid=26611>. Acesso em: 10 abr. 2019. 